\title{
Medium-term morphodynamic behavior of a multiple sand bar beach.
}

\author{
Elaine Siqueira Goulart† and Lauro Júlio Calliari†
}

$\dagger$ LOG, Instituto de Oceanografia, Universidade federal do Rio Grande, Av. Itália, s/n, km 08, Bairro Carreiros, Rio Grande, RS,96203-900, BR. elainegoulart@gmail.com lcalliari@log.furg.br

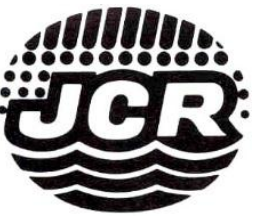

www.JCRonline.or

\section{ABSTRACT}

Goulart,E.S., Calliari, L.J.,2013. Medium-term morphodynamic behavior of a multiple sand bar beach. In: Conley, D.C., Masselink, G., Russell, P.E. and O'Hare, T.J. (eds.), Proceedings $12^{\text {th }}$ International Coastal Symposium(Plymouth, England), Journal of Coastal Research, Special Issue No. 65, pp. 1774-1779, ISSN 0749-0208.

Cassino beach, located in southern Brazil, is a very fine sand beach with morphodynamic stages ranging from dissipative to intermediate. This beach can display up to three sand bars which are active during high energy events. Since the beach is located in a microtidal area, flood events are mainly caused by storm surges which can reach $1.8 \mathrm{~m}$ During such events the highest rates of beach erosion are observed. A series of six years (from March 2005 to February 2011) of data from video images have been used to study the nearshore morphodynamic behavior. Daily data of sandbars and waterline position were obtained from these images. The generated data was analyzed in order to recognize flood events patterns as well as patterns of beach morphodynamic both during flood events and during normal conditions. Forty seven flood events were identified, 53\% during winter, 24\% during autumn, $17 \%$ during spring, and $6 \%$ in the summer. The average duration of events is 1.5 days. During this period, the whole system is migrating offshore in a rate of $9 \mathrm{~m} /$ year. Wavelet analysis showed a gradation of frequencies that govern the variability of the surf zone features. Closer to the beach high frequencies processes (associated with tides and meteorological forcing) have larger influence than further offshore, where longer processes gain importance.

ADDITIONAL INDEX WORDS: Beach morphodynamics, sandbars, migration rates, flood events

\section{INTRODUCTION}

On most natural beaches, unconsolidated sediments are arranged by wave action into a set of patterns, known collectively as the beach morphodynamic. The most common features are sandbars, which, typically, are shore parallel to rhythmic or irregular shoals. Sandbars are often found at locations having surf zones, whose width is modulated by variations in the incident wave climate (Plant et al., 1999). These features are generally located in water depths shallower than $8 \mathrm{~m}$ and are often oriented shore parallel, but also contain alongshore nonuniformities, such as rip channels or crescentic plan shapes (van Enckevort and Ruessink, 2003).

Changes in sandbar morphologies in association with changing wave conditions are often striking and have been extensively documented(Wright and Short, 1984; Lippmann and Holman, 1990).

Cross-shore sandbar migration has been studied at various sites around the world, differing in environmental parameters such as sediment characteristics and the wave and tidal regime. However, general behavior has been described by Komar (1998) as wave depending, where small waves drives onshore sediment transport and onshore migration, and larger waves induces offshore sediment transport and offshore sandbar migration.

Located at the Rio Grande do Sul State (RS), southern Brazil, Cassino Beach is part of a long uninterrupted sandy beach of 220 kilometers long (Figure 1). Cassino Beach morphodynamic behavior has been topic of some previous work. The beach has been described, based on the morphodynamic classification proposed by Wright and Short (1984), as oscillating among the dissipative modal state, of larger frequency in the autumn and

DOI: 10.2112/SI65-300.1 received 30November 2012; accepted Day Month 2013.

(c) Coastal Education \& Research Foundation 2013 winter, and secondary intermediate states in the spring and summer (Calliari and Klein, 1993; Tozzi and Calliari, 2000; Guedes et al., 2010; Pereira et al., 2010). Focusing on the surf zone of RS beaches, some studies highlight the occurrence of three to four sandbars (Pereira and Calliari, 2005; Pereira et al., 2006)

The beach response to storm surges has been studied by Calliari et al.(1998), Saraiva et al.(2003) and later by Parise et al.(2009). According the authors, meteorological tide events were mostly associated with extratropical cyclones occurring over the ocean. Events that cause greater erosion at Cassino Beach occurred when the cyclones originated in the south of Uruguay with an eastward displacement, generating waves that reach the beach from SE.

All these studies were very important for the knowledge about the Cassino Beach system behavior, however they have the limitation of short data series. None of them used data series longer than two years. Only after the installation of Argus station in 2005 (four cameras monitoring the beach and surf zone system hourly, for more information consult Holland et al.(2009), a continuous data series is being acquired, and now is starting to be analyzed, providing a better understanding of the system on larger time scales.

The main goal of this paper is to investigate the sandbars behavior and waterline position daily from March 2005 to February 2011, during flooding events and normal conditions.

\section{Field Site}

Beaches at this area are mainly dissipative and thus are flat and wide, being composed of very fine quartz sand (Calliari et al., 1998). Net litoral drift is toward northeast. The wave climate is dominated by wind sea and relatively young swells. Mean significant height of $1.0 \mathrm{~m}$ from E/SE quadrant, with a period ranging from 10 to $12 \mathrm{~s}$, which corresponds to swell conditions; 


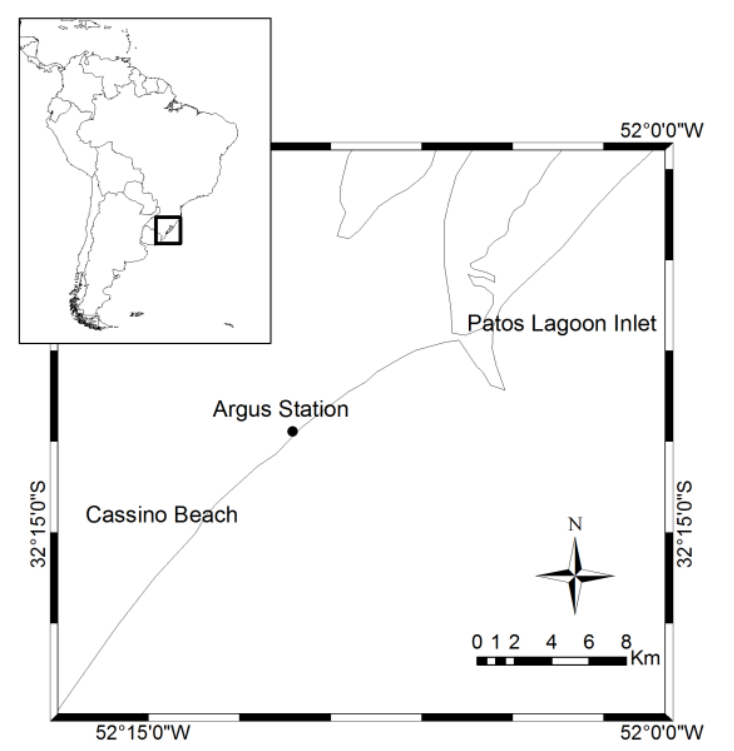

Figure 1-Study area. Location of the Argus Station, at Cassino Beach, south of Patos Lagoon Inlet.

and a mean significant height of $1.5 \mathrm{~m}$ from $\mathrm{S} / \mathrm{SE}$ quadrant with a period ranging from 6 to $8 \mathrm{~s}$, which corresponds to sea conditions (Strauch, 1998).

Regarding the wind, Northeasterly (NE) winds dominate throughout the year. Southwesterly (SW) winds have their importance increased during fall and winter as frontal systems become more frequent over this area. Typical wind speeds are between 3 and $5 \mathrm{~m} \mathrm{~s}^{-1}$ (Möller et al., 2001).

Since the beach is located in a microtidal area, where maximum astronomical tidal range is $0.47 \mathrm{~m}$ (Möller et al., 2001), flood events are mainly caused by storm surges which can reach up 2 meters (Calliari et al., 1998).

\section{METHODOLOGY}

\section{Argus images}

The Argus camera network consists of video cameras installed over high land areas or in towers at many beach locations around the globe (Holman and Stanley, 2007). At Cassino Beach, the station is composed by four cameras installed at the top of a $14 \mathrm{~m}$ tower (Figure 1).

Each daylight hour, the station's cameras acquire a timeexposure (timex) image created by averaging over several hundreds of consecutive images collected at $1 \mathrm{~Hz}$. Such procedure reveal one or more smooth white bands of breaking waves. The oblique images of the individual cameras can be merged and rectified (Holland et al., 1997) to yield a single planview image. The continuous high-intensity bands that are manifested in the planview images serve as a reasonable estimate for the submerged sandbars, and can be extracted from the images by tracking the alongshore maxima intensity (van Enckevort and Ruessink, 2001).

\section{Features location}

In the present work an algorithm based on maximum pixel intensity within a region of interest (Barline Intensity Mapper BLIM) developed by van Enckevort and Ruessink (2001) was applied to the daily mean of timex images (called from now on daytimex) of each day available from March 2005 to February
2011 in order to identify the position of the three Cassino's sandbars over the time.

The waterline location were extracted daily from the daytimex images using the methodology described in Aarninkhof et $a l$.(2003) that uses clustering of sub-aqueous and sub-aerial pixels in 'Hue-Saturation-Value' (HSV) color space and identify their boundary. This methodology was used by Sobral et al. (this volume) with Cassino Beach data. The authors find out root mean square errors of about $10 \mathrm{~m}$ and correlation coefficient of 0.82 between data extracted from images and beach profiles collected simultaneously the images.

As stated before, the tidal range in the study area is very small, and once we are using day averaged images, we are extracting mean features location, what minimizes the tide effect on the data. After all, the data were alongshore averaged to yield one feature location value per day.

\section{Flood events identification}

Considering the absence of sea level data, the flood events identification was performed using the waterline position data. Every position greater than two times the total series standard deviation, in the onshore direction, was considered a flood event. Consecutive days of flooding were considered the same event. An similar methodology was used by Campos et al. (2010) for extreme events identification.

\section{Migration Rates}

Migration rates were computed as the temporal derivative of sandbars and waterline location as described by van Enckevort and Ruessink (2003).

\section{Wave data}

Wave data were obtained from the NOAA/NCEP wave generation model WAVEWATCH III (Tolman, 1999), that runs based on the NCEP wind data reanalysis. Daily significant wave height $\left(H_{s}\right)$, ranging from March 2005 to February 2011, were extracted from the NWW3 operational wave model hindcast reanalysis, available for downloading at the internet website http://polar.ncep.noaa.gov/waves.

\section{Time series analysis}

In order to analyze localized variations of the periodical signals within the time series, wavelet analysis (Torrence and Compo,

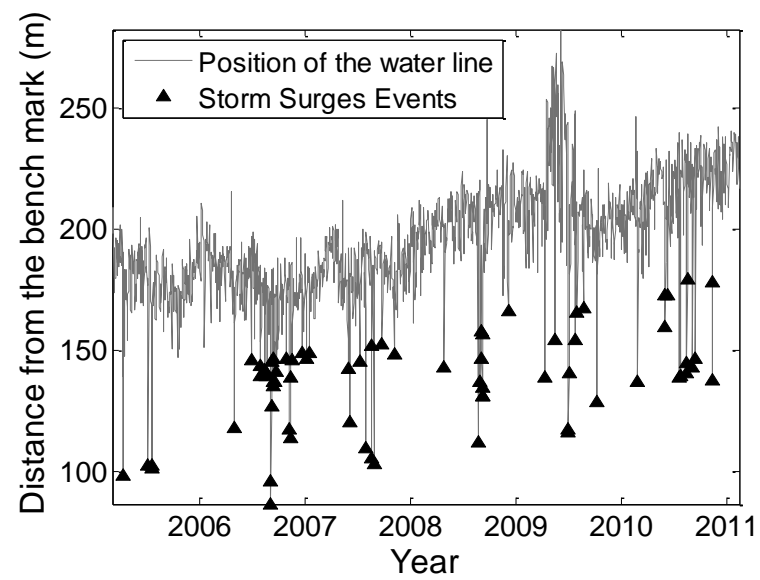

Figure 2 - Waterline position along the time. The black triangles denote the occurrence of flood events. 


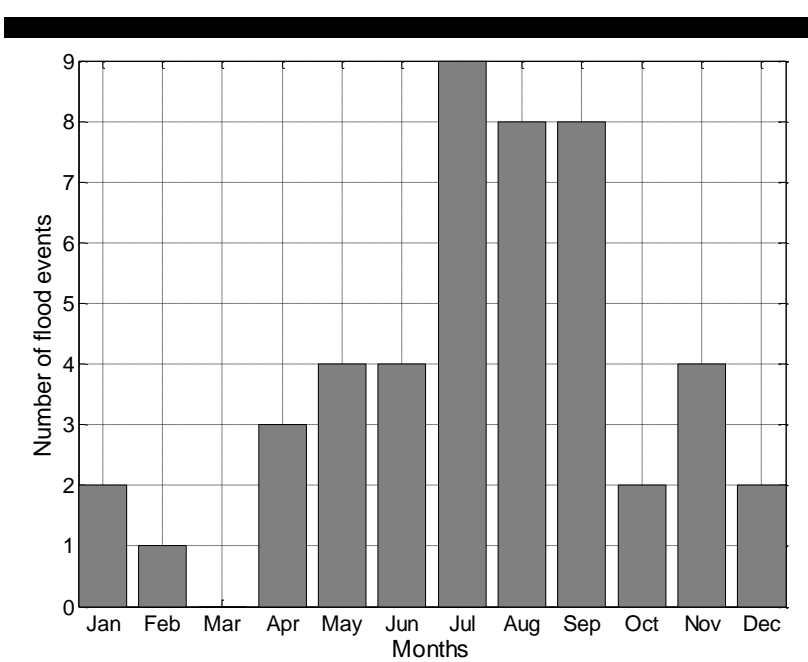

Figure 3 - Occurrence of flood events distribution by month.

1998) were applied to each data series. Given a time/space series, wavelet analysis can locate signals at individual frequencies/wavenumbers in the temporal/spatial domains. Wavelet analysis achieves this by transforming the data into translated and dilated multiples of the so-called "mother wavelet". The Morlet mother wavelet was used on the analysis.

\section{RESULTS AND DISCUSSION}

\section{Flood events occurrence}

Figure 2 shows the results of flood events identification based on the waterline position. Forty seven events were identified during the study period, totaling sixty nine days of flooding. Events lasted on average 1.5 days and a maximum of 6 days. The mean interval between events is 44 days, the minimum 2 and maximum 286 days.

Fifty three percent of the flood events occurred during winter, $24 \%$ during autumn, $17 \%$ during spring, and $6 \%$ in the summer (Figure 3). The study carried out by Parise et al. (2009) from June 2006 to July 2007 indicated that the events were more frequent in autumn and winter, with $35 \%$ predominance in each season, followed by spring $(17 \%)$ and summer $(13 \%)$ in that period. The

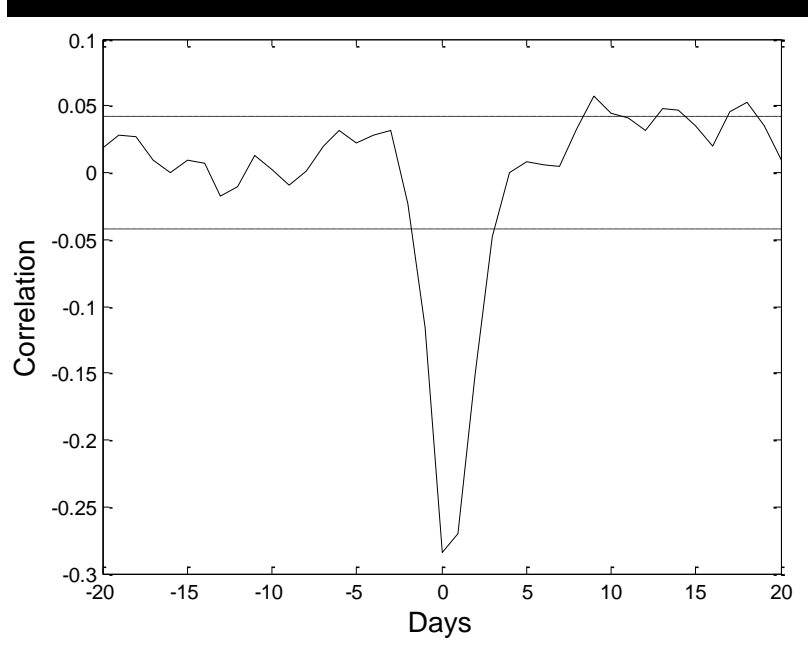

Figure 4 - Cross correlation between $\mathrm{H}_{\mathrm{s}}$ and waterline position. differences between the along year distribution of events in the different studies is probably due to the annual variability that is evident in Figure 2. Another explanation may be the change on the occurrence of meteorological events that cause the flood, which could cause a change on the pattern of flooding occurrence.

The cross-correlation between waterline and $H_{s}$ is shown on Figure 4. The correlation exists, is significant, has zero lag, and is negative. It means that when a change in wave height occurs (usually associated with storms) there is a rapid change in the waterline position, in opposite direction. The increase in $\mathrm{H}_{\mathrm{s}}$ display the waterline position towards the benchmark. However, the low value of this correlation (-0.28) indicates that much of waterline position variability cannot be explained by $H_{s}$ changes. The pressure gradient between continent and ocean may be an important factor as pointed out by Marone and Camargo (1994), besides wind speed and direction, but these data were not available for this study. Maia (2011) calculated the average percentage contribution of each forcing that comprises the total rise in sea level during the implementation of an analytical model and found that the wind was the main agent responsible for $43 \%$ of positive fluctuations in sea level.

\section{Morphodynamic Behavior}

Figure 5 displays the distance of the features regarding the bench mark location along the six years. Closer to the bench mark are waterline data, followed by inner, middle and outer sandbars.

A preliminary overview of these features indicates a large variability along the years. It is noticeable that the feature's onoffshore migration rates vary in a large range of time scales. However, as indicated by the dashed dotted-lines, all features (sandbars and waterline) display a clear tendency to an offshore migration, at an almost constant rate of $9 \mathrm{~m} / \mathrm{yr}$.

Beach profiles measured since 2006 showed the growth of the dune field at this site. Foredune height has increased from $3.5 \mathrm{~m}$ in 2006 to $5.5 \mathrm{~m}$ in 2012 and the dune toe migrated 50 meters offshore in 6 years. The beach trend associated with the dune behavior indicates that the system as a whole is accreting, and the offshore migration is not only part of some inter annual cycle.

Lélis and Calliari (2006) analyzing shoreline changes between 1947 and 2000 near lagoonal and river stabilized inlets in Rio Grande do Sul State, southern Brazil found that Cassino beach displayed the higher accretion rates $(4.10 \mathrm{~m} / \mathrm{y})$.

Table 1 presents means, standard deviations (STDs) and maximum values of all features position data, during flood events and normal conditions. All data had as reference the bench mark position. Waterline mean position was $195 \mathrm{~m}$, inner bar $257 \mathrm{~m}$, middle bar $319 \mathrm{~m}$ and outer bar $435 \mathrm{~m}$ from the bench mark. The values obtained in this study agree with those found by Guedes et al. (2010), who focused on Cassino Beach morphodynamic behavior from April to June of 2005 through Argus images and beach profiles. The authors described mean values of $238 \mathrm{~m}$ to inner bar, $299 \mathrm{~m}$ to middle bar and $437 \mathrm{~m}$ to outer bar. Although these values are within the STDs encountered in this study (Table 1 ), the larger values found here for both the inner and middle sandbars position may be an indication that the system is undergoing accretion and consequently is migrating offshore.

During flood events outer bar mean values showed a slight increase (to 322 on middle bar and 461 to outer bar), smaller than was expected. However the inner bar value decreased to $253 \mathrm{~m}$. This behavior can be explained by the weak correlation of $H_{s}$ and events occurrence. Sandbars tend to be forced in offshore direction in periods of high waves (Plant et al., 1999). As events discussed in this work are not always linked with high waves, the impact of them on average values is smoothed. That can be reinforced by 


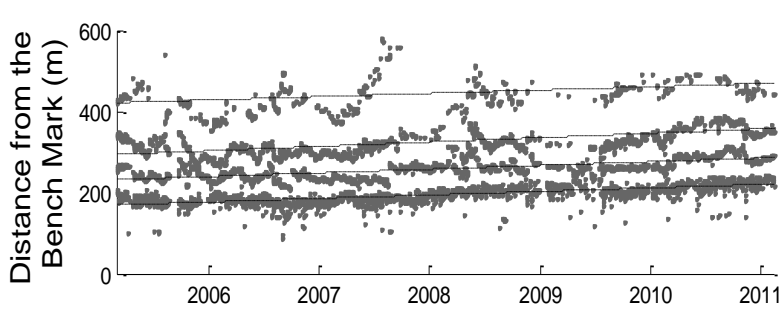

Figure 5 -Sandbars and waterline location from 2005 to 2011. Near to the bench mark are waterline data, followed by inner, middle and outer sandbars. Dash-dotted lines are features trends.

looking at maximum sandbars position values (Table 1), which for inner and middle bars are not coincident with flood events values.

The waterline's behavior is obviously opposite to outer sandbars behavior, since a flood event implies that the interface between the ocean and continent is further onshore than in normal conditions. Therefore the mean position value decreases during flood events to $158 \mathrm{~m}$ away from the bench mark.

The STDs values increase from the inner to the outer bar $(26 \mathrm{~m}$, $29 \mathrm{~m}$ and $36 \mathrm{~m}$, Table 1), indicating that the further offshore the sandbar is, the greater is the variability in its position. Komar (1998) points out that the highest waves break over the deepest bars (further offshore) and progressively lower breakers occur over the inner bars. During periods of low waves, they pass over the deep outer bars without appreciable effect and do not break until they reach the comparatively shallow water over the inner bar. It is also known (Gallagher et al. 1998; Plant et al. 1999, among others) that higher waves tend to force bigger changes on sandbars position. The association of both effects, results in higher sandbars positions STDs on deepest sandbars data.

During events occurrence STDs values also tend to increase, particularly on further onshore sandbars and waterline (to 26 and $34 \mathrm{~m}$ respectively), reflecting the change in hydrodynamic condition reaching the shallowest portion of the surf zone.

The sandbars offshore migration rates ( ) are larger than onshore. This behavior have been described by Plant et al. (1999). Offshore migration rates tend to be associated with higher waves that force higher rates of sediment transport, while onshore migration rates are linked with lower waves, and lower sediment transport rates.

Table 1-Sandbars and waterline positions. All values are in meters.

\begin{tabular}{lcc}
\hline \hline & Normal Condition & Event Condition \\
\hline Inner bar & & \\
\hline Mean & 257.07 & 253.28 \\
Std. & 22.64 & 26.08 \\
Max. & 371.11 & 314.9 \\
\hline Middle Bar & & \\
\hline Mean & 319.04 & 322.12 \\
Std. & 26.44 & 29.34 \\
Max. & 430.42 & 428.7 \\
\hline Outer Bar & & \\
\hline Mean & 435.39 & 461.27 \\
Std. & 37.35 & 36.76 \\
Max. & 578.56 & 578.56 \\
\hline Waterline & & \\
\hline Mean & 195.16 & 158.17 \\
Std. & 23.16 & 34.25 \\
Max. & 282.59 & 255.27 \\
\hline
\end{tabular}

Waterline rates are always larger than sandbars rates. This happens because waterline position reflects the actual sea level, which is affected by wind, waves and pressure field with very small delay (Pugh, 1987). Moreover, sandbars rates reflect the speed of feature movement, which implies in lots of sediment transport and interaction with the local hydrodynamic (Komar, 1998).

The migration rates mean values for Cassino Beach sandbars are comparable (even though twice as large) to values found on other multiple-bar systems, and follow the tendency of larger rates on offshore direction. van Enckevort and Ruessink (2003) reported values of $1.04 \mathrm{~m} /$ day and $1.17 \mathrm{~m} /$ day for onshore and offshore migration rates of the inner bar, and $1.2 \mathrm{~m} /$ day and 1.57 $\mathrm{m} /$ day on outer bar for a double barred nearshore at Noordwijk, Netherlands. Mean values for Duck, NC, USA (another double barred beach) by Wolf (1997) are also on the same order magnitude of the values found in this study.

The large migration rates on Cassino Beach may relate to its grain size characteristics which are mainly composed of very fine sand. The other beaches used for comparison are composed of fine to medium sand. The finer sediment is easily transported, and the sandbar migration rate is higher than sandbar systems composed of fine to medium sand.

Comparing migration rates on normal conditions (

) and event conditions it is possible to note a considerable increase in the values, on both directions, however with a greater increase towards offshore. This increase, particularly on offshore direction, was expected, as the increase of sandbars position STDs (Table 1), due the increase of hydrodynamic conditions during flood events. The high variability of onshore

rates may be related with the processes described by Plant et al. (1999). The authors discuss about the changes in sandbars with increasing hydrodynamic and notice that there is an increase in onshore migration rates, which occurs before the change from onshore to offshore migration as the energy increases.

\section{Time series analysis}

The wavelet analyses of all data are shown on Figure 6 . The areas inside the contour lines represent data inside the $5 \%$ of statistical significance. The dotted lines represent the occurrence of a flood event.

The wavelets analysis of the waterline data (Figure 6 - A) shows the highest energy events at high frequency band, from 1 to 14 days. In the same figure is possible notice the coincidence

Table 2 - Migration Rates. All values are in meters per day

Table 2 - Migration Rates. All values are in meters per day

\begin{tabular}{|c|c|c|c|c|}
\hline & \multicolumn{2}{|c|}{ Normal Condition } & \multicolumn{2}{|c|}{ Event Condition } \\
\hline & Onshore & Offshore & Onshore & Offshore \\
\hline \multicolumn{5}{|c|}{ Inner bar } \\
\hline Mean & 2.06 & 2.35 & 2.99 & 3.04 \\
\hline Std. & 2.67 & 3.75 & 3.03 & 5.98 \\
\hline Max. & 48.04 & 51.88 & 17.15 & 50.4 \\
\hline \multicolumn{5}{|c|}{ Middle Bar } \\
\hline Mean & 2.53 & 2.98 & 4.9 & 5.7 \\
\hline Std. & 3.79 & 4.52 & 11.36 & 12.09 \\
\hline Max. & 81.80 & 80.89 & 81.80 & 80.89 \\
\hline \multicolumn{5}{|c|}{ Outer Bar } \\
\hline Mean & 1.78 & 2.4 & 2.77 & 3.08 \\
\hline Std. & 3.65 & 4.43 & 6.28 & 5.44 \\
\hline Max. & 46.11 & 46.97 & 37.58 & 43.17 \\
\hline \multicolumn{5}{|c|}{ Waterline } \\
\hline Mean & 9.55 & 8.53 & 36.21 & 26.47 \\
\hline Std. & 13.48 & 10.94 & 31.38 & 22.01 \\
\hline iMaxsu & 65186913 & 103.43 & 118.67 & 103.43 \\
\hline
\end{tabular}

\footnotetext{
Table 2 - Migration Rates. All values are in meters per day
} 

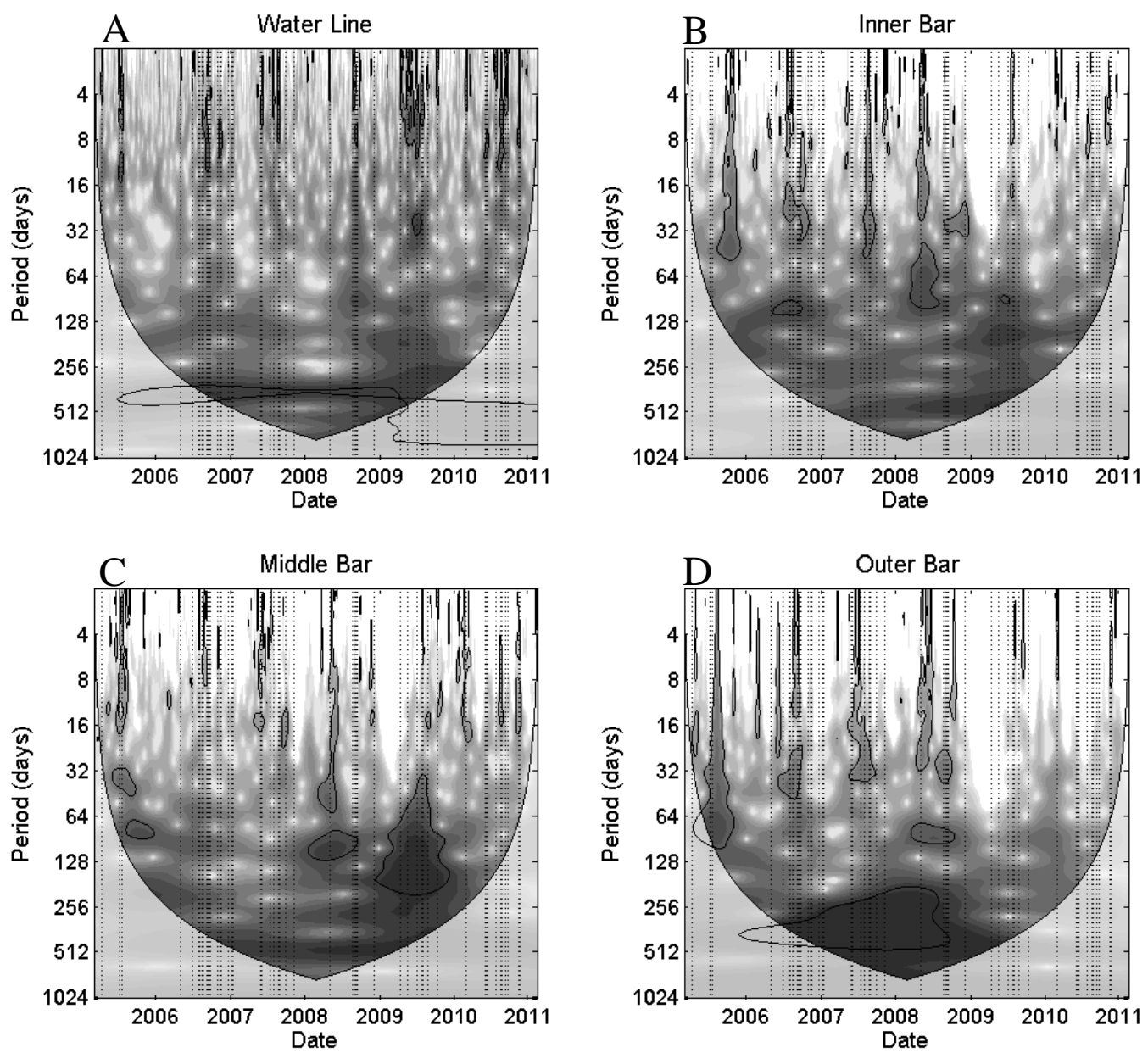

Figure 6 - Wavelets analysis. Dotted lines indicate the occurrence of flood events.

between these events and the ocureence of flood events (dotted vertical lines). The absence of significant data on higher periods highlights that the variance of waterline positon data is exclusively due high frequence processes.

The inner bar analysis (Figure 6-B) shows high energy in high frequencies such as the waterline position, but there is high energy also in periods up to 128 days, indicating greater importance of longer variability in the inner bar than in the waterline.

The low frequencies for sandbars variability are related to seasonal to interannual variabilities. Seasonal variabilities are well known and are related to changes in wave, pressure and wind fields that occurs during the year (Reboita et al., 2006). The lowest frequencies (from 300 to 500 days) may be related to phenomena like ENSO, but longer data series and more extensive analysis are needed to really understand this scale of processes over the behavior of surf zone features

Middle bar wavelets (Figure 6-C) shows less energy in lower periods and an increase in the energy on higher periods, up to 200 days, and this tendency still increases in outer bar wavelets (Figure 6-D), where there is a high energy peak on periods up to 500 days.

The high energy frequencies identified coincide with frequencies found by other authors studing other oceanographic and meteorological phenomena in the same region. Costa and Möller (2011)studying the coastal currents variablity around Rio
Grande found similar frequencies ranges (from 5 to 12 days) on currents and wind data and related them to meteorological forcing as cold front passages and extratropical cyclones. Reboita et al.(2006) investigating the climate variability in Rio Grande associated periods from 4 to 12 days to the passage of frontal systems. Guedes et al.(2010) also described high frequencies variation on Cassino beach profiles. All these findings lead us to sugest that the high frequency variability on surf zone is extremely linked with the extratropical cyclones and the cold fronts associated with them.

\section{CONCLUSIONS}

Flood events were more frequent during winter, followed by autumn, spring and summer. Events lasted on average 1.5 days and maximum 6 days. The mean interval between events is 44 days, the minimum 2 and maximum 286 days.

There are evidences that the beach system is accreting and migrating offshore at a rate of $9 \mathrm{~m} /$ year. Outer sandbars presented larger STDs position during normal conditions, and these values are even larger during events, mostly on the inner bar, due the change on hydrodynamic conditions.

Offshore migration rates are larger than onshore. Due to the action of higher waves, outer sandbar migration rates are larger than inner bar rates. Probably due to its finer sand composition, 
sandbar migration rates for Cassino beach are larger when compared to other multiple-bar systems.

The wavelets analysis showed a very well-marked change on dominant time scales on surf zone features on Cassino Beach. There is a clear increase on the periods that dominate the variability of the features from waterline, where high frequencies as tides and meteorological forcing are completely dominant, and the outer bar, that is very influenced by processes with periods up to 500 days.

\section{ACKNOWLEDGEMENT}

We would like to thank CAPES ("Coordenação de Aperfeiçoamento de Pessoal de Nível Superior") for the Phd. scholarship.

\section{LITERATURE CITED}

Aarninkhof, S.G.J., Turner, I.L., Dronkers, T.D.T., Caljouw, M., Nipius, L., 2003. A video-based technique for mapping intertidal beach bathymetry. Coastal Engineering, 49, $275-$ 289.

Calliari, L.J., Klein, A.H.F., 1993. Características Morfodinâmicas e Sedimentológicas das Praias Oceânicas Entre Rio Grande e Chuí, RS. Pesquisas em geociências, 20, 48 - 56.

Calliari, L.J., Tozzi, H.A.M., Klein, A.H.F., 1998. Beach Morphology and Coastline Erosion Associated with Storm Surges in the Southern Brazil - Rio Grande to Chuí, RS. Anais Da Academia Brasileira De Ciencias, 70, 231-247.

Campos, R.M., Camargo, R.D.E., Harari, E.J., 2010. Caracterização de eventos extremos do nível do mar em santos e sua correspondência com as reanálises do modelo do ncep no sudoeste do atlântico sul. Revista Brasileira de Meteorologia, 25, 175-184.

Costa, R. de L., Möller, O.O., 2011. Estudo da estrutura e da Study of the structure ans variability of currents in the area of inner shelf off Rio Grande (RS, Brazil), southwest of the South Atlantic during srping-summer 2006 - 2007. Journal of Integrated Coastal Zone Management, 11, 273-281.

Gallagher, E.L., Elgar, S., Guza, R.T., 1998. Observation of sand bar evolution on a natural beach. Journal of Geophysical Research, 103, $3203-3215$.

Guedes, R.M.C., Calliari, L.J., Pereira, P.S., 2010. Morfodinâmica da praia e zona de arrebentação do Cassino, RS através de técnicas de vídeo imageamento e perfis de praia. 36, 165180.

Holland, K.T., Holman, R.A., Lippmann, T.C., Stanley, J., Plant, N.G., 1997. Practical use of video imagery in nearshore oceanographic field studies. Journal of Oceanic Engineering, 22, 81-92.

Holland, K.T., Vinzon, S.B., Calliari, L.J., 2009. A field study of coastal dynamics on a muddy coast offshore of Cassino beach, Brazil. Continental Shelf Research, 29, 503-514.

Holman, R.A., Stanley, D.J., 2007. The history and technical capabilities of Argus. Coastal Engineering, 54, 477-491.

Komar, P., 1998. Beach processes and sedimentation., Second Edi. ed. Second Edi. ed Prentice-Hall, Inc., Englewood Cliffs, NJ

Lippmann, T.C., Holman, R.A., 1990. The Spatial and Temporal Variability of Sand Bar Morphology. Journal of Geophysical Research, 95, 11,575-11,590.

Lélis, R.J.F., Calliari, L.J., 2006. Historical Shoreline Changes Near Lagoonal and River Stabilized Inlets in Rio Grande do Sul State, Southern Brazil . Journal of Coastal Research, 2004, 301-305.
Maia, N.Z., 2011. Avaliação da elevação do nível do mar e riscos de inundação costeira associados à passagem de ciclones no Balneário Hermenegildo, RS. Universidade do Rio Grande, 104 pp.

Marone, E., Camargo, R., 1994. Marés meteorológicas no litoral do Estado do Paraná: o evento de 18 de agosto de 1993. Nerítica,

Möller, O.O., Castaing, P., Salomon, J.-C., Lazure, P., 2001. The Influence of Local and Non-local Forcing Effects on the Subtidal Circulation of Patos Lagoon. Estuaries, 24, 275289.

Parise, C.K., Calliari, L.J., Krusche, N., 2009. Extreme storm surges in the south of Brazil: atmospheric conditions and shore erosion. Brazilian Journal of Oceanography, 57, $175-188$.

Pereira, P. de S., Calliari, L.J., Barletta, R.D.C., 2010. Heterogeneity and homogeneity of Southern Brazilian beaches: A morphodynamic and statistical approach Continental Shelf Research, 30, 270-280.

Pereira, P.S., Calliari, L.J., 2005. Variação morfodinâmica diária da praia do Cassino, RS, durante os verões de 2002/2003 no setor terminal turístico. Brazilian Journal of Aquatic Science and Technology, 9, 7-11.

Pereira, P.S., Calliari, L.J., Lélis, R.J.F., 2006. High Frequency Beach Profile Monitoring: Implications in Beach Safety at Cassino Beach, Southern Brazil . 2004, 2004-2007.

Plant, N.G., Holman, R.A., Freilich, M.H., 1999. A simple model for interannual sandbar behavior. 104, 755-776.

Pugh, D.T., 1987. Tides, Surges and Mean Sea - Level, First Edit. ed. First Edit. ed Johm wiley \& Sons, Chichester/ New York/ Brisbane/ Toronto/ Singapore, 472 pp.

Reboita, M.S., Krusche, N., Piccoli, H.C., 2006. Climate variability in Rio Grande, RS, Brazil: a quantitative analysis of contributions due to atmospheric systems. Revista Brasileira de Meteorologia, 21, 256-270.

Saraiva, J., Bedran, C., Carneiro, C., 2003. Monitoring of Storm Surges on Cassino Beach. Journal Of Coastal Research Special Issue, 35, 323-331.

Sobral, F.C., Pereira, P. de S., Cavalcantio, P., Guedes, R.M., Calliari, L.J., 2013. Intertidal Bathymetry Estimate Using Video Images in a Dissipative Beach. Journal of Coastal Research,.

Strauch, J.C., 1998. Um Ano de Monitoramento de Ondas em Rio Grande. Rio Grande, XI Semana Nacional de Oceanografia.

Tolman, H.L., 1999. User manual and system documentation of WAVEWATCH-III version 1.18. 118.

Torrence, C., Compo, G.P., 1998. A Practical Guide to Wavelet Analysis. Bulletin of the American Meteorological Society, 79, 61-78.

Tozzi, H.A.M., Calliari, L.J., 2000. Portal de Periódicos. Pesquisas em geociências, 27, 29-42.

Wolf, F.C.J., 1997. Hydrodynamics, sediment transport and daily morphological development of a bar-beach system. Utrecht University, $267 \mathrm{pp}$.

Wright, L.D., Short, A.D., 1984. Morphodynamic variability of surf zones and beaches: a synthesis. Marine Geology, 56, 93-118.

van Enckevort, I.M.J., Ruessink, B.G., 2001. Effect of hydrodynamics and bathymetry on video estimates of nearshore sandbar position. Journal of Geophysical Research, 106, 16,969-16,979.

van Enckevort, I.M.J., Ruessink, B.G., 2003. Video observations of nearshore bar behaviour. Part 1: alongshore uniform variability. Continental Shelf Research, 23, 501-512. 